\title{
Malignant pleural mesothelioma: an update on investigation, diagnosis and treatment
}

\author{
Anna C. Bibby ${ }^{1,2}$, Selina Tsim ${ }^{3,4}$, Nikolaos Kanellakis 5,6 , Hannah Ball ${ }^{6,7}$, \\ Denis C. Talbot ${ }^{7}$, Kevin G. Blyth ${ }^{3,8}$, Nick A. Maskell ${ }^{1,2}$ and loannis Psallidas ${ }^{5,6}$
}

Number 4 in the Series "Pleural Diseases"

Edited by Najib Rahman and loannis Psallidas

\begin{abstract}
Affiliations: ${ }^{1}$ Academic Respiratory Unit, University of Bristol, Bristol ,UK. ${ }^{2}$ North Bristol NHS Trust, Bristol, UK. ${ }^{3}$ Queen Elizabeth University Hospital, Glasgow, UK. ${ }^{4}$ Institute of Cancer Sciences, University of Glasgow, Glasgow, UK. ${ }^{5}$ Respiratory Trials Unit, University of Oxford, Churchill Hospital, Oxford, UK. ${ }^{6}$ Oxford Centre for Respiratory Medicine, Churchill Hospital, Oxford, UK. ${ }^{7}$ Dept of Oncology, Oxford University Hospitals NHS Foundation Trust, Oxford, UK. ${ }^{8}$ Institute of Infection, Immunity and Inflammation, University of Glasgow, Glasgow, UK.
\end{abstract}

Correspondence: Anna C Bibby, Academic Respiratory Unit, 2nd Floor Learning \& Research Building, Southmead Hospital, Bristol, BS10 5NB, UK. E-mail: Anna.Bibbyabristol.ac.uk

ABSTRACT Malignant pleural mesothelioma is an aggressive malignancy of the pleural surface, predominantly caused by prior asbestos exposure. There is a global epidemic of malignant pleural mesothelioma underway, and incidence rates are predicted to peak in the next few years.

This article summarises the epidemiology and pathogenesis of malignant pleural mesothelioma, before describing some key factors in the patient experience and outlining common symptoms. Diagnostic approaches are reviewed, including imaging techniques and the role of various biomarkers. Treatment options are summarised, including the importance of palliative care and methods of controlling pleural effusions. The evidence for chemotherapy, radiotherapy and surgery is reviewed, both in the palliative setting and in the context of trimodality treatment. An algorithm for managing malignant pleural effusion in malignant pleural mesothelioma patients is presented. Finally new treatment developments and novel therapeutic approaches are summarised.

$\circ$ @ERSpublications

This article on mesothelioma describes pathogenesis, symptoms, diagnostic approaches and treatment options http://ow.ly/cjkb305aQGz

\begin{abstract}
Previous articles in this series: No. 1: Psallidas I, Kalomenidis I, Porcel JM, et al. Malignant pleural effusion: from bench to bedside. Eur Respir Rev 2016; 25: 189-198. No. 2: Bhatnagar R, Corcoran JP, Maldonado F, et al. Advanced medical interventions in pleural disease. Eur Respir Rev 2016; 25: 199-213. No. 3: Bintcliffe OJ, Lee GYC, Rahman NM, et al. The management of benign non-infectious pleural effusions. Eur Respir Rev 2016; 25: 303-316.
\end{abstract}

Received: July 012016 | Accepted after revision: Oct 122016

Support statement: N. Kanellakis has received a short-term fellowship from the European Respiratory Society (STRTF 2015-9508). K.G. Blythe is the recipient of an NHS Research Scotland Career Research Fellowship. N.A. Maskell has received an unrestricted research grant from CareFusion and has sat on the advisory board for CareFusion. I. Psallidas is the recipient of a European Respiratory Society Fellowship (RESPIRE2 - 2015-7160). Funding information for this article has been deposited with Open Funder Registry.

Conflict of interest: Disclosures can be found alongside this article at err.ersjournals.com

Provenance: Submitted article, peer reviewed.

Copyright OERS 2016. ERR articles are open access and distributed under the terms of the Creative Commons Attribution Non-Commercial Licence 4.0. 


\section{Introduction}

Malignant pleural mesothelioma (MPM) is an aggressive cancer of the pleural surface. It is associated with previous asbestos exposure, with a latency period of $\sim 40$ years between fibre exposure and disease presentation [1-5].

Global incidence of MPM has risen steadily over the past decade, and is predicted to continue to an estimated peak in 2020 [1,2]. Precise numbers are difficult to determine as the disease is likely to be under reported in areas of low incidence. However, an estimate based on 2008 data suggested an average of 14200 cases worldwide each year [6]. Total incidence is highest in the USA and UK although per capita, Australia and Italy also rank highly. Unfortunately the ongoing, unregulated use of asbestos in industrial countries such as India, Brazil and Russia means that MPM will continue to represent a significant global health concern even after peak incidence has passed.

Prognosis with MPM is poor and median survival ranges from 8 to 14 months from diagnosis $[1-3,7]$. Women have a more favourable outlook than men, but due to the occupational nature of the disease there is a male predominance of 4:1 [7]. There are four main histological sub-types; epithelioid, sarcomatoid, biphasic or mixed, and desmoplastic. The sarcomatoid variant is associated with the worst outcomes, with a median survival of just 4 months. In contrast, epithelioid has the most favourable prognosis with a median survival of 13.1 months [1,2,7].

This article will summarise the pathogenesis of MPM, before describing symptoms and exploring elements of the patient's experience. Diagnostic approaches, including biomarkers and radiological imaging will be outlined. The evidence for chemotherapy, radiotherapy and surgery will be reviewed and new directions for the future will be presented.

\section{Pathogenesis}

The majority of MPM cases are caused by prior exposure to asbestos, often occurring $>40$ years previously [1-5]. Asbestos is a naturally occurring silicate mineral that has two different structural forms: the curly, serpentine fibres of chrysotile or "white" asbestos and the sharp, needle-like fibres of amphibole asbestos. The latter can be further divided into crocidolite (blue) asbestos, amosite (brown) asbestos, and anthophyllite, actinolite and tremolite. The risk of developing MPM is related to the type of fibre, as well as to the heaviness and duration of exposure [1].

MPM is classified as an occupational disease since asbestos exposure occurs mainly in the workplace. However, para-occupational exposure can occur, for instance in wives of asbestos workers who launder their clothes $[1,4]$. Additionally, asbestos exposure may have occurred outside the workplace or could have happened unbeknownst to the patient.

Other causes of MPM include erionite (a mineral found in the rocks of Turkey), chest wall radiation and simian virus 40. The latter, an oncogenic virus that blocks tumour suppressor genes, may act as a cofactor in the development of MPM, although the evidence for causality is weak [1, 5, 8-12].

The mechanism of carcinogenesis in MPM is multifactorial. Asbestos fibres are inhaled and migrate to the pleura. Within the pleural space, fibres cause irritation and a repeated cycle of tissue damage and repair is established. The presence of oxygen free radicals, released by asbestos fibres when phagocytosed by macrophages, causes intra-cellular DNA damage and abnormal repair [5]. Asbestos fibres also penetrate mesothelial cells, where they interfere with mitosis, generate mutations in DNA and alter chromosome structure. Asbestos-exposed mesothelial cells release inflammatory cytokines, including tumour growth factor- $\beta$, platelet-derived growth factor and vascular endothelial growth factor (VEGF) [5]. This creates a favourable microenvironment for tumour growth. Finally, asbestos induces the phosphorylation of various protein kinases (mitogen-activated protein and extracellular signal-regulated kinases 1 and 2), leading to increased expression of proto-oncogenes and further promotion of abnormal cellular proliferation [13].

Genetic profiling of MPM tumours has unveiled common mutations, including reduced expression of key molecules in the p53 tumour-suppressor gene pathway, such as p14, p16 and NF2-MERLIN [13]. Deletions and loss mutations of other genes, including BRCA-associated protein 1 (BAP1), set domain containing 2 (SETD2), DDX3X, unc-like autophagy activating kinase (ULK2), ryanodine receptor 2 (RR2), cilia and flagella associated protein 45 (CFAP45), set domain bifurcated 1 (SETDB1) and DDX51, have also been demonstrated in MPM [14]. However, compared to many tumours, MPM has a low frequency of protein-altering mutations ( $\sim 25$ mutations per tumour) [15]. This limits the potential for molecular targeted therapy as oncogene-addiction is less likely to occur in MPM [16].

\section{The patient's perspective}

Informing someone that they have MPM is, whilst necessary, often devastating for the patient. They face a barrage of bad news relating to the incurable nature of MPM, its poor prognosis and the limited treatment options. 
As a result, many patients are left with feelings of hopelessness and uncertainty about the future [17-19]. Depression and anxiety are common and found more frequently in MPM compared with other tumours $[17,20-22]$.

The classification of MPM as an industrial injury generates complex compensation and benefits claims, which can be time-consuming and stressful $[18,22]$. Legal requirements after death, such as coroner's inquests and potentially a post mortem, create an additional burden for family members [18, 19, 22, 23]. The occupational nature of MPM can create feelings of anger towards previous employers or concern for family members and colleagues who may have been similarly exposed [24]. Some patients will have seen colleagues die of MPM and describe a sense of anticipatory anxiety, known as the "Damocles syndrome", created by the knowledge that they are similarly at risk [22, 24].

Therefore, accurate and sensitively delivered information is crucial. In the UK mesothelioma specialist nurses are a valuable resource in this regard. They act as key workers, offering practical and emotional support, and providing a consistent presence at clinic appointments. Their presence can reduce patients' experience of care as "fragmented" and ameliorate anxiety by providing continuity and consistency [23]. In centres where specialist nurses are not available, all team members should collaborate to ensure they are providing integrated care for the complex needs of individual patients.

\section{Symptoms}

The majority of patients with MPM present with breathlessness, chest pain or both [1,2, 18, 25-30].

In the early stages of disease breathlessness is usually due to a pleural effusion, found in $70 \%$ of patients at presentation [25]. However, as the disease progresses, pleural effusions tend to diminish, either as a result of medical intervention or obliteration of the pleural space by the tumour [25]. As the disease extends around the pleural surface, breathlessness occurs as a result of restricted respiratory movement and encasement of the lung by the tumour $[1,25]$.

Chest pain is common and can be caused by the effusion or the tumour. It is usually dull and heavy and sometimes described as a "dragging" sensation [1,31]. Pleuritic pain is less common, but can occur in the presence of parietal pleural irritation [1, 2, 27]. Chest pain tends to worsen as the disease progresses, particularly if invasion of the chest wall occurs [32]. Bone pain secondary to rib invasion or neuropathic pain from intercostal nerve involvement may also feature [31, 32].

Other symptoms of MPM include fatigue, anorexia, weight loss, sweats and malaise [1, 2, 18, 25-29, 31]. These are a result of circulating cytokines, released by both the tumour and host in response [33]. Cough, haemoptysis and lymphadenopathy are less common in MPM compared with bronchogenic tumours [1]. However, local tumour invasion can cause superior vena cava obstruction, laryngeal nerve palsy or dysphagia $[1,2,25]$. The latter is often a pre-terminal event [1].

Some patients are asymptomatic, and have an abnormality detected on imaging undertaken for a different reason [1]. Asymptomatic patients appear to have longer survival, probably because they are diagnosed earlier in the disease process [34]. For this reason it is important to carefully monitor patients who present with a pleural effusion with a background of previous asbestos exposure, even if the effusion is small or resolves spontaneously. A proportion of these patients will develop MPM in the future, and active follow-up increases the chance of making the diagnosis early in these people [35].

\section{Diagnosis}

MPM is a challenging diagnosis to make. Radiological imaging should be undertaken in all patients as it can provide valuable diagnostic and staging information. The advantages and limitations of the different imaging modalities are outlined below.

Biomarkers are useful diagnostic and prognostic tools in other cancers [36, 37]. In MPM a number of different biomarker tests have been evaluated. However, to date, MPM biomarkers have been found to be imperfect and of limited clinical use. The evidence is summarised below.

Further investigation of suspected MPM requires sampling of pleural fluid for biochemical and cytological examination. Unfortunately, cytological yield is low in MPM, and biopsies are usually required to confirm the diagnosis and identify the histological sub-type [1, 35, 38]. Biopsies can be obtained percutaneously under radiological guidance, or under direct vision at thoracoscopy, either as a local anaesthetic procedure (medical thoracoscopy) or as a surgical intervention (video-assisted thoracoscopic surgery (VATS)) [39]. The choice of biopsy technique will vary between patients depending on the distribution and morphology of their disease, their suitability for surgery or invasive procedures and the availability of services [39]. The evidence for the various biopsy approaches has been discussed elsewhere and is not included in this article [39]. 


\section{Staging}

Staging MPM is difficult due to limitations in current imaging techniques, specifically in the accurate assessment of tumour size and nodal involvement [2]. Surgical thoracoscopy, with additional mediastinoscopy to assess suspected nodal disease, is superior to computed tomography (CT) and is the current gold standard for staging in MPM [40]. However, not all patients are suitable to undergo this procedure, and therefore image-based staging, whilst imperfect, is employed for many MPM cases.

There are a number of staging classifications for MPM, all of which have limitations for use in routine clinical practice [2]. The consensus is that a tumour, node, metastasis-based system, using surgical information where available and radiology in its absence, should be employed to determine prognostic outlook in all patients with MPM. One such system is the International Mesothelioma Interest Group staging classification (table 1) [41].

\section{Imaging}

Imaging plays a major role in the assessment of patients with suspected MPM, and can contribute both diagnostic and staging information. However, radiological interpretation can be difficult if pleural thickening is minimal or absent, and staging is often challenging due to the heterogeneous growth pattern of the tumour.

Chest radiography is usually the first investigation performed. Typical findings include a pleural effusion, loss of hemithoracic volume, nodular pleural thickening, irregular fissural thickening or a localised mass lesion. The presence of pleural plaques may alert the clinician to prior asbestos exposure, even in the absence of known exposure. However, chest radiograph appearances are generally insensitive and nonspecific and further imaging is usually required [42].

Bedside thoracic ultrasound is commonly performed by respiratory physicians to assess pleural fluid volume, distribution and echogenicity, and to determine a safe site for aspiration [43]. Thoracic ultrasound allows visualisation of pleural fluid, pleural thickening and any tumours or nodularity on the pleura or hemidiaphragm (figure 1). Sonographic features that suggest pleural malignancy include pleural-based mass lesions, pleural thickening $>1 \mathrm{~cm}$, nodular pleural thickening and diaphragmatic nodularity [44]. These features have a specificity of $>95 \%$ with regard to malignancy [44]. However, sensitivity is low at $40 \%$, and consequently patients with nonspecific thoracic ultrasound findings require further investigation if MPM is suspected.

CT imaging is vital in patients with MPM. CT features of pleural malignancy include pleural enhancement, infiltration of the chest wall, mediastinum or diaphragm, nodular or mediastinal pleural thickening and interlobar fissural nodularity [45]. Some studies have reported high sensitivity and specificity associated with these features; however, appearances can be subjective and are highly operator dependent. A recent review of the "real-life" diagnostic performance of CT reported a sensitivity and specificity of $68 \%$ and $78 \%$, respectively, for pleural malignancy [46]. CT cannot reliably differentiate MPM from metastatic pleural malignancy, although circumferential pleural thickening and mediastinal pleural involvement are more

\section{TABLE 1 The International Mesothelioma Interest Group Staging System for malignant pleural mesothelioma}

\section{T}

T1 Tumour of the ipsilateral parietal pleura, including diaphragm and mediastinal pleura

T1a No visceral pleural involvement

T1b With visceral pleural involvement

T2 Tumour affecting parietal, visceral, diaphragmatic and mediastinal pleura, with either involvement of diaphragmatic muscles or pulmonary parenchyma

T3 Involvement of the endothoracic fascia, extension into the mediastinal fat, non-transmural involvement of the pericardium or resectable focus of chest wall invasion

T4 Unresectable disease, diffuse chest wall or mediastinal involvement, direct transdiaphragmatic spread into the peritoneum, contralateral plural involvement, invasion of the spine, ribs or brachial plexus, trans-mural pericardial invasion or malignant pericardial effusion

$\mathbf{N}$

No No regional lymph node metastases

N1 Metastases in ipsilateral bronchopulmonary or hilar lymph nodes

N2 Metastases in subcarinal or ipsilateral mediastinal lymph nodes, including ipsilateral internal mammary chain

N3 Contralateral lymph node metastases, ipsilateral or contralateral supraclavicular lymph node involvement, and scalene nodes

M

M0 No extrathoracic metastases

M1 Extrathoracic metastases present

Reproduced from [41] with permission from the publisher. 
FIGURE 1 Ultrasound demonstrating large echoic effusion (A) above a flattened diaphragm (B) with extensive thick, irregular nodularity arising from the diaphragm (C) and visceral pleural (D). This is highly suspicious for malignancy, most likely malignant pleural mesothelioma.

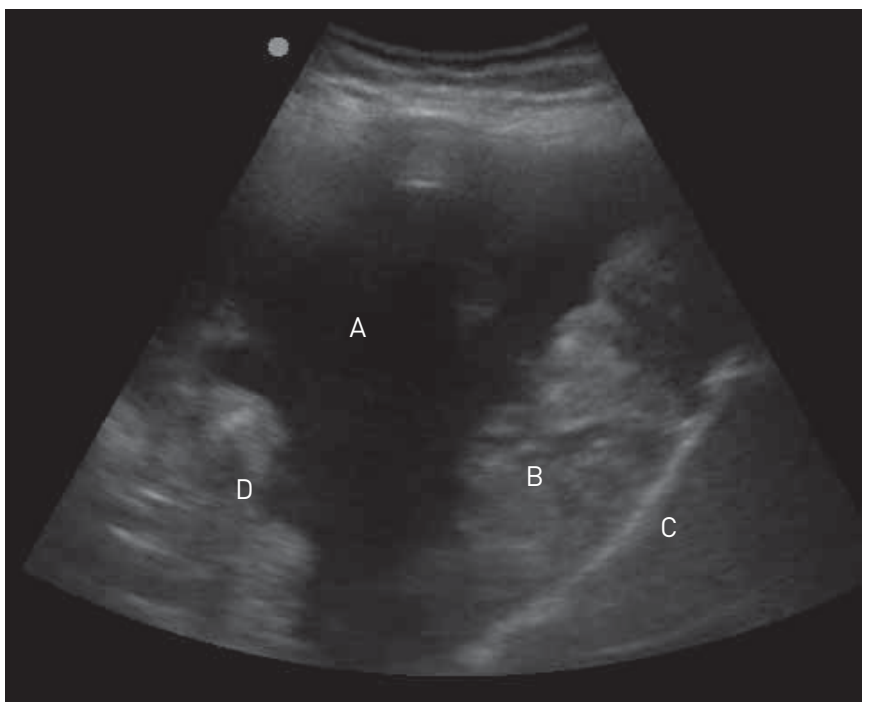

frequent in MPM [47]. Similarly CT cannot reliably distinguish between MPM subtypes, although ipsilateral volume loss, interlobar fissural involvement and mediastinal pleural involvement are reported more frequently in sarcomatoid disease $[48,49]$.

CT staging is useful in MPM, as advanced stage disease is associated with worse prognoses [50]. However, accurate staging can be challenging as identification of nodal metastases is difficult on CT and subtle chest wall or diaphragm invasion may be missed [40]. Further imaging with positron-emission technology (PET)-CT or magnetic resonance imaging (MRI) can provide additional information in this regard.

PET-CT combines high-resolution CT scanning with an injection of a radioactive metabolic tracer (e.g. 18-fluoro-deoxy-glucose (FDG)) which accumulates at areas of metabolic activity (figure 2). FDG uptake is assessed at regions of interest and reported as standardised uptake values (SUV). Maximum SUV is higher in MPM than benign disease, and a threshold value of 2 can reliably differentiate between benign and malignant disease $[51,52]$. However, PET-CT cannot identify MPM from metastatic pleural malignancy, and there does not appear to be any correlation between maximum SUV and histological sub-type [51]. Because FDG uptake is a marker of metabolic activity, false negatives are possible in early disease or in tumours with a low proliferation rate. Conversely, inflammatory disorders such as rheumatoid pleuritis and tuberculous pleurisy can produce false-positive results, as can prior pleurodesis [53]. Consequently, sensitivity and specificity are not high enough to support the use of PET-CT in routine diagnostic practice, although it may have a role in identifying suitable targets for biopsy [54]. PET-CT is also able to identify malignant nodal disease and extrathoracic metastases with greater accuracy than CT or MRI and may have a role in staging, particularly in patients undergoing surgery $[55,56]$.

Unfortunately, PET-CT suffers from poor spatial resolution, which results in low sensitivity for extrapleural invasion. MRI is superior in this regard with excellent spatial and contrast resolution. In a prospective series of 69 patients being considered for surgical resection, contrast-enhanced MRI detected the presence of chest wall, mediastinal or diaphragmatic involvement in 17 (22\%) patients in whom CT had not demonstrated invasive disease [57]. The sensitivity for detecting T3 disease with MRI was $85 \%$,

FIGURE 2 FDG 118-fluoro-deoxyglucose)-positron emission tomography showing malignant pleural mesothelioma. A: an area of high FDG uptake (maximum standardised uptake value of 13.4) in the left lateral pleura beneath the third rib. B: a right paratracheal lymph node with maximum standardised uptake value of 4.6

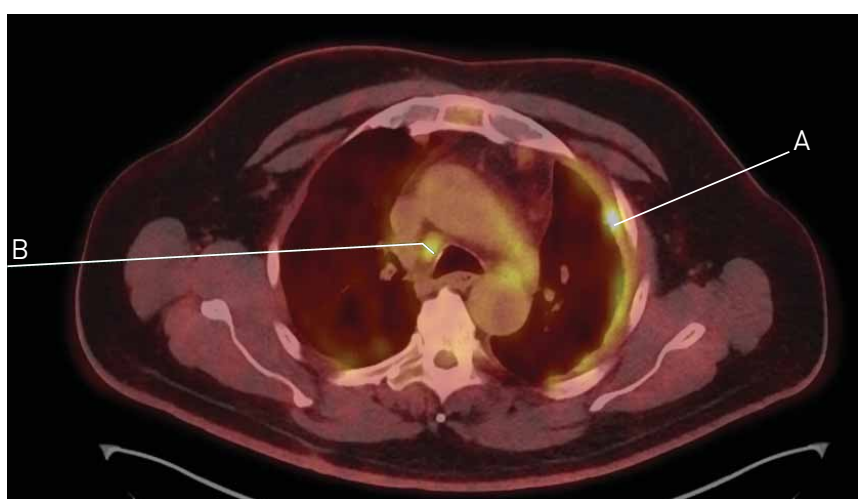


with $100 \%$ specificity. Consequently MRI is useful in assessing for infiltrative disease that would preclude surgical resection.

As well as identifying morphological features of malignancy, MRI can provide functional information via the use of contrast agents, e.g. gadolinium, or methods such as diffusion-weighted imaging-MRI or dynamic contrast enhancement-MRI. Combining functional data with standard imaging produces sensitivity and specificity rates $>90 \%$ for differentiating malignant pleural disease from benign $[45,58,59]$. Despite this, MRI is not routinely used for diagnostic purposes in MPM.

\section{Biomarkers}

A reliable diagnostic biomarker that offers high diagnostic sensitivity and specificity would be a major advancement for MPM. However, despite promising early results no such biomarker has been identified. Studies have been disadvantaged by retrospective designs, use of selected MPM cohorts, inappropriate controls and inconsistent sampling protocols, assay methods and cut-off points. The most widely studied and promising markers are summarised below.

Mesothelin is a cell-adhesion glycoprotein that is over-expressed in MPM [60, 61]. Serum mesothelin (or serum mesothelin-related protein) levels are elevated in patients with MPM in comparison to asbestos-exposed controls $[62,63]$. The diagnostic value of mesothelin appears to be highest in patients with advanced stage epithelioid tumours [64]. It is less useful in sarcomatoid sub-types as these tumours rarely express mesothelin. A meta-analysis of data from 4491 individuals, of whom 1026 had MPM, reported a sensitivity of $32 \%$ for serum mesothelin with $95 \%$ specificity [64]. This is insufficient for diagnostic purposes [38]. Pleural fluid mesothelin levels share similar diagnostic performance rates to serum, with a meta-analysis of 11 studies calculating an overall sensitivity and specificity of $<60 \%$ and $90 \%$, respectively [65]. Consequently, a high serum or pleural fluid mesothelin level should prompt further investigations for malignancy, but a negative test is of limited value.

Other blood-based biomarkers that have been explored in MPM include megakaryocyte potentiating factor (an alternative cleavage product of the mesothelin precursor protein) and the glycoproteins osteopontin and fibulin 3. Studies of these biomarkers suffered from methodological problems including inconsistent diagnostic cut-off levels and lack of external validation [62, 66-68]. However, none of these biomarkers have demonstrated diagnostic superiority over mesothelin and consequently they have no role in clinical care at present. Fibulin 3 is also found in pleural fluid, and high levels appear to correlate with advanced disease [67]. Its diagnostic ability is limited, but it may be of value as a prognostic tool $[66,67]$.

Recently, a proteomics-based biomarker detection technique has been developed in the form of SOMAscan (SomaLogic Inc., Boulder, CO, USA). This 13-protein classifier differentiated MPM from controls with a sensitivity and specificity of $93 \%$ and $91 \%$, respectively, but external validation is required [69]. Interestingly, the 13 proteins used in this technology have not previously been associated with MPM and their identification may provide potential targets for novel drugs or diagnostic strategies.

\section{Management}

There is no curative treatment for MPM. Systemic treatment options include chemotherapy, targeted therapy and radiotherapy, delivered separately or as part of multimodality treatment. Surgery is controversial and limited to patients with early stage disease and good functional status. Palliative care and symptom management are essential and the control of pleural effusions is an important factor. A number of novel therapeutic agents are under investigation, and may provide further treatment options for MPM in the future.

MPM patients should be discussed at a specialist mesothelioma multidisciplinary team meeting, as recommended in the 2007 UK Department of Health's Mesothelioma Service Framework and the British Thoracic Society's Statement on Mesothelioma [1, 70]. Discussion at a specialist multidisciplinary team provides expert advice on investigation and management, as well as additional benefits such the opportunity to participate in clinical trials $[70,71]$.

\section{Chemotherapy}

Chemotherapy is the only treatment modality that has been shown to improve survival in MPM. However, prior to 2003 the evidence was poor and based on underpowered, early phase trials [72]. Response rates were low and survival was universally $<10$ months [73]. One large randomised trial demonstrated that the addition of chemotherapy to active symptom control offered no survival benefit and no improvement in quality of life compared with active symptom control alone [28].

However, in 2003 two pivotal phase III trials were published that changed the landscape of chemotherapy in MPM [74, 75]. The trials used third-generation anti-folate agents aimed at inhibiting DNA synthesis and preventing tumour proliferation. The first trial randomised 448 treatment-naïve participants to receive 
either pemetrexed and cisplatin or cisplatin alone [74]. Median survival in the pemetrexed arm was 12.1 months, compared with 9.3 months with cisplatin alone $(\mathrm{p}=0.02)$. Toxicity rates were high initially, but fell after the addition of vitamin B12 and folic acid supplementation. On the basis of this trial, pemetrexed was approved by global marketing authorities for use in combination with cisplatin for MPM. Over 10 years later, it remains the standard first-line chemotherapy for patients with MPM.

The second trial compared raltitrexed and cisplatin with cisplatin alone in 250 participants [75]. Survival benefit was similar to that seen in the pemetrexed trial ( 11.4 months versus 8.8 months, $\mathrm{p}=0.048$ ) although objective response rates were lower $[74,75]$. The study appeared underpowered, and consequently had less impact on clinical care. At present raltitrexed is not licenced by the US Food and Drug Administration or the European Medicines Agency for use in MPM.

Carboplatin can be substituted for cisplatin in older patients, patients with comorbidities or patients who experience toxicity with cisplatin, as it is generally better tolerated. In a meta-analysis, carboplatin demonstrated similar efficacy to cisplatin, and phase II trials have shown enhanced overall survival and longer progression-free survival (PFS) in patients with MPM treated with carboplatin and pemetrexed [76-79].

An important issue in MPM chemotherapy is predicting which patients will respond to treatment. An evaluation of over 1700 patients who received pemetrexed with either cisplatin or carboplatin as part of an expanded access programme demonstrated response rates of $26.3 \%$ and $21.7 \%$, respectively [80]. These low response rates, combined with a lack of reliable biomarker to identify potential responders, are likely to be responsible for the low uptake of chemotherapy in some centres [7].

There are many unanswered questions regarding chemotherapy and MPM. It is not known whether immediate chemotherapy is more effective than chemotherapy delayed until the appearance of symptoms. A small pilot study suggested a trend for slower progression and longer survival with early chemotherapy, but larger trials are needed [29]. Similarly, the optimum number of cycles of chemotherapy and the role of maintenance pemetrexed are unclear. In nonsmall cell lung cancer, four cycles of chemotherapy has similar efficacy to six cycles, but with lower toxicity [81]. Could the same be true for MPM? Alternately, is there any benefit from continuing pemetrexed as maintenance therapy following an initial response? Maintenance pemetrexed is safe and well-tolerated, but randomised efficacy data is awaited [82]. Finally the best second-line agent is unknown. Phase II trials support the use of vinorelbine, or gemcitabine/ cisplatin doublet, but re-treatment with pemetrexed may also be effective in previous responders [83-87].

\section{Targeted therapy}

VEGF plays a key role in MPM by promoting angiogenesis and stimulating tumour growth [5, 88]. Recently, bevacizumab, an anti-VEGF monoclonal antibody, has been shown to be effective in MPM [89]. The multicentre, phase III MAPS trial randomised 448 participants with MPM to receive cisplatin and pemetrexed chemotherapy with or without bevacizumab. Patients who received bevacizumab had significantly longer median (95\% CI) overall survival at 18.8 (15.9-22.6) months compared with 16.1 (14.0-17.9) months in the chemotherapy alone arm $(\mathrm{p}=0.017)$. Patients given bevacizumab alongside chemotherapy also showed longer PFS of 9.2 (8.5-10.5) months versus 7.3 (6.7-8.0) months in those receiving standard care $(\mathrm{p}<0.0001)$ [89]. This difference was seen despite a higher proportion of patients stopping bevacizumab early, and a greater number of post-study treatments given to the control group. Adverse event rates were similar between groups, although thromboembolic complications and kidney impairment were more common with bevacizumab. The authors conclude that the use of bevacizumab is warranted alongside first-line standard chemotherapy in patients with unresectable MPM [89]; an opinion that is supported by an editorial in the same journal [90].

\section{Radiotherapy}

Radiotherapy is used in two main settings in MPM: as a palliative measure to treat symptoms or an adjuvant to surgery and chemotherapy in the context of trimodality treatment. Evidence for the latter technique is limited to anecdotal reports in highly selected patients, and as a result trimodality treatment is not considered standard care for MPM. The literature relating to trimodality treatment is reviewed in a later section.

Radiation is administered using the highly precise intensity-modulated radiotherapy technique as the alternative, high-dose external-beam hemithoracic radiotherapy, was associated with significant toxicity. Intensity-modulated radiotherapy technique allows accurate three-dimensional mapping of the tumour, thus reducing the likelihood of radiation injury to surrounding organs [91]. Nonetheless, toxicity remains a risk, with eight (30\%) out of 27 patients experiencing radiation pneumonitis in a recent phase II study [91].

In the palliative setting, radiotherapy can reduce tumour bulk and relieve symptoms, particularly in the context of chest wall invasion, nerve root involvement or painful cutaneous metastases. The prospective phase II SYSTEMS trial showed that a dose of $20 \mathrm{gy}$, delivered in five daily fractions, reduced 
patient-reported pain scores by $\geqslant 30 \%$ in $14(35 \%)$ out of 40 participants [92]. Further trials evaluating the optimum radiotherapy dose and choice of regimen are underway.

Radiotherapy has been used prophylactically to prevent sub-cutaneous metastases developing due to tumour seeding along procedure tracts. One small randomised trial using three daily fractions of $7 \mathrm{gy}$ after thoracoscopy resulted in no tract metastases in the treatment group compared with eight (40\%) out of 20 patients in the control arm [93]. However, this result has never been replicated, and subsequent randomised trials reported no difference in tract metastases following prophylactic radiotherapy $[94,95]$. The only suitably powered, randomised trial to date reported no difference in the frequency of tract metastases in patients receiving immediate radiotherapy after large-bore chest interventions compared with those receiving it when required. Consequently, the use of prophylactic radiotherapy is likely to diminish.

\section{Surgery}

The benefit of surgery in MPM is much debated, and there is a need for robust randomised trial data to elucidate its efficacy and clarify its role in management [1,96, 97].

There are two approaches to surgery in MPM: radical removal of all visible disease or a more conservative, tissue-sparing, debulking procedure. The more radical option is extrapleural pneumonectomy (EPP), an operation which aims to eradicate all macroscopic tumour via the removal of lung, pleura, pericardium and diaphragm [98]. The original descriptions of EPP reported enhanced survival, but mortality and complication rates were high [98-101]. Additionally, these reports were based on retrospective data from highly selected patients, with no control arm and no information about the population from which they were drawn. Consequently, a systematic review concluded that it was impossible to determine whether EPP extended survival in people with MPM [102].

The only randomised trial to assess EPP in MPM was the Mesothelioma and Radical Surgery trial (MARS), a feasibility study whose primary aim was to determine whether a full-scale trial would be possible [103]. The trial experienced practical issues, including lengthy recruitment and non-compliance with randomisation (six out of 26 participants allocated to "no EPP" sought and received surgery off-trial). Analysis of clinical outcome data revealed potential harm associated with EPP with an adjusted hazard ratio for death of 2.75 (95\% CI 1.21-6.26; $\mathrm{p}=0.016)$. As a result of this, and observational studies suggesting similarly poor outcomes, EPP has been largely abandoned in favour of less radical procedures [104-107].

Extended pleurectomy with decortication (also known as pleurectomy and decortication or pleurectomy/ decortication) is a lung-sparing procedure in which the visceral and parietal pleura are removed. It is associated with fewer surgical complications than EPP, and potentially better survival [105, 107-109]. PD is a "de-bulking" procedure, and unlike EPP does not aim for macroscopic complete resection. Consequently it is often employed alongside multi-modality treatment [109-113]. To date, there is no randomised data focussing on whether PD extends survival compared with no surgery; however, the multicentre MARS-2 trial is currently underway and aiming to answer this question [114].

Another non-radical approach is partial pleurectomy via VATS. Non-randomised studies suggested that VATS-partial pleurectomy controlled symptoms in MPM, and possibly improved survival [115, 116]. However, the only suitably powered randomised trial to examine this demonstrated no survival difference compared with talc pleurodesis via a chest drain [117]. VATS-partial pleurectomy had higher rates of pleurodesis in the first 12 months, but at the expense of a greater number of surgical complications and a longer hospital stay. Consequently VATS-partial pleurectomy cannot be recommended for MPM, and non-surgical pleurodesis methods should be employed to control pleural fluid.

\section{Trimodality treatment}

Trimodality treatment for MPM consists of induction chemotherapy followed by EPP with subsequent hemithoracic radiotherapy. Non-randomised studies in carefully selected patients reported median survival times of up to 29 months and a systematic review concluded that trimodality treatment may be beneficial for certain patients [118-120]. However, a subsequent large randomised trial reported no difference in PFS or overall survival in patients treated with neoadjuvant chemotherapy and EPP with or without radiotherapy [121]. There were 12 adverse events of grade 3 or higher in 27 patients treated with radiotherapy, including one death from radiation pneumonitis. The study concluded that the addition of hemithoracic radiotherapy to EPP and chemotherapy added an unnecessary burden without offering benefit.

An alternative approach involves delivering high-dose radiotherapy prior to EPP, followed by adjuvant chemotherapy if there is lymph node involvement at surgery. This approach, nick-named SMART (Surgery for Mesothelioma After Radiation Therapy), was shown to be feasible in an initial series of 25 patients and appeared to be particularly efficacious in patients with epithelioid sub-type tumours [122]. 
Updated results for 62 patients treated with SMART showed a median survival of 36 months, with greatest benefit again seen in patients with epithelioid tumours [123]. However, it must be noted that these reports represent highly selected patients, operated on in a single centre with extensive MPM expertise and the results may not be generalisable. At present trimodality treatment is not recommended in the standard care pathway for MPM.

\section{Management of malignant pleural effusions}

The majority of patients with MPM experience a pleural effusion at some point. Drainage of pleural fluid improves breathlessness and prevention of fluid re-accumulation can improve quality of life long term [124]. There are a number of methods for achieving pleural fluid control, each with benefits and disadvantages. A flowchart to help decide which procedure is best for an individual patient is shown in figure 3 .

Therapeutic pleural aspiration is the simplest approach, and most patients will undergo this intervention at least once in their disease pathway. However, fluid inevitably re-accumulates and further interventions are required [30, 72]. Repeated aspirations may be appropriate for patients with a very short life expectancy, but a definitive procedure is generally preferable $[2,30,72]$.

Definitive fluid control can be achieved with chemical pleurodesis, a procedure aiming to obliterate the pleural space and render fluid re-accumulation impossible. For successful pleurodesis to occur there must be direct apposition of enough healthy pleural tissue to allow pleural inflammation and adhesion to occur when a chemical irritant is instilled into the pleural space. Consequently patients with trapped lung or extensive tumour bulk should be considered for alternative methods of pleural fluid control.

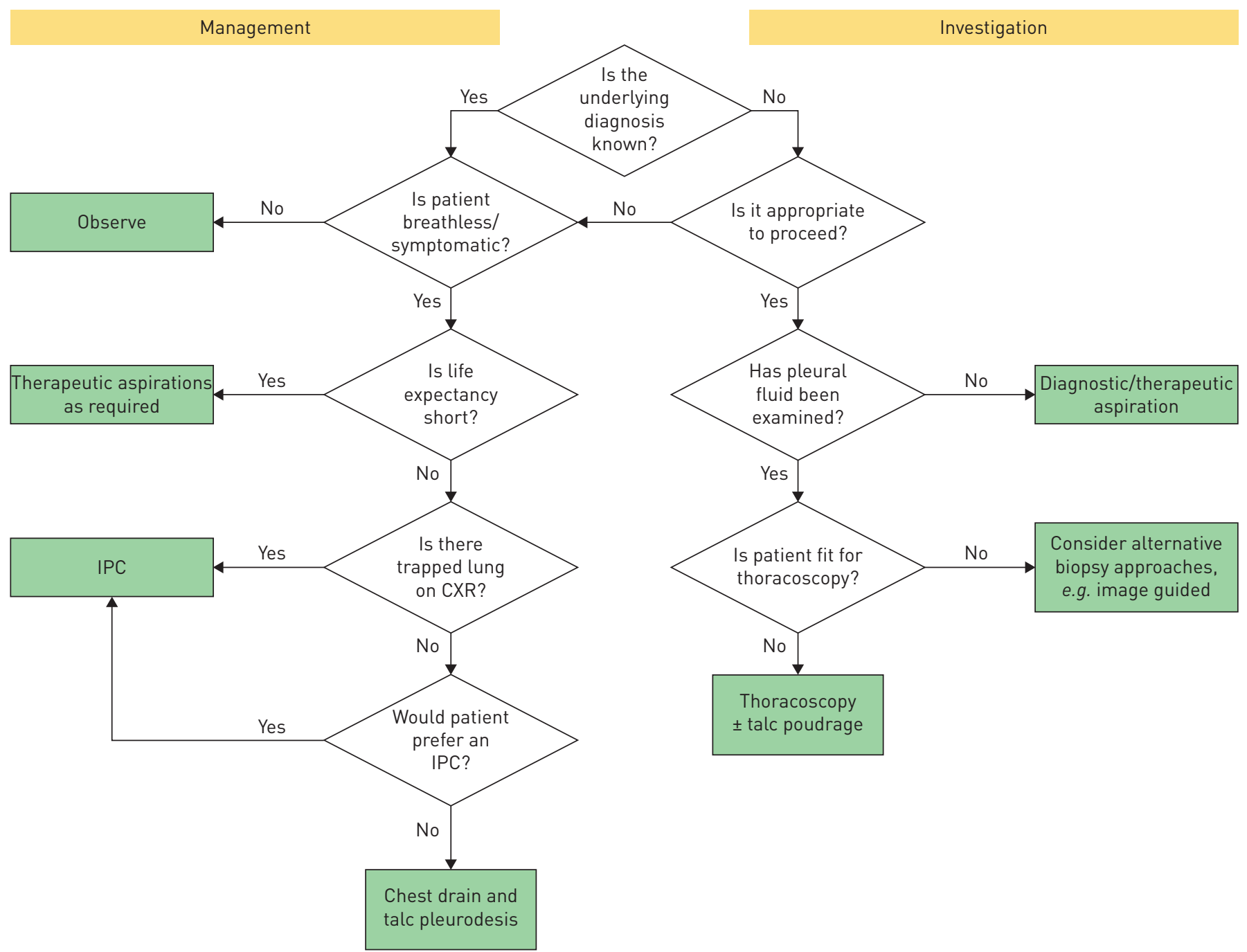

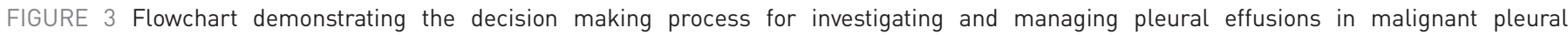
mesothelioma. IPC: indwelling pleural catheter; CXR: chest radiograph. 
Many chemical agents have been used for pleurodesis, but sterile, medical-grade talc appears to be the safest and most effective [125-129]. The British Thoracic Society recommends talc as the pleurodesis agent of choice, although other agents such as bleomycin and tetracycline are used in other countries [30, 130].

Talc can be delivered into the pleural space as thoracoscopic poudrage (figure 4) or as slurry via a chest drain. Talc pleurodesis is successful in $60-80 \%$ of people provided the underlying lung is not trapped [ 30 , $124,131]$. There is weak evidence suggesting poudrage may be more effective than slurry, but access to thoracoscopy is not universal and some patients may not be suitable for this more invasive procedure [132-134]. For those that are, thoracoscopy has the additional benefit of allowing patients to obtain a diagnosis and undergo pleurodesis in one sitting [39].

An alternative to pleurodesis is the placement of an indwelling pleural catheter. This allows regular home drainage, and provides long-term relief of breathlessness [124]. Indwelling pleural catheters are as effective at relieving symptoms as talc slurry via a chest drain, and have the additional benefit of being appropriate for patients with trapped lung [124]. In situations where both indwelling pleural catheters and talc pleurodesis are available, management should be led by patient choice [135].

\section{Palliative care}

The British Thoracic Society, the European Respiratory Society and the International Mesothelioma Interest Group all emphasise the importance of good palliative care to help manage physical symptoms and offer psychological, emotional or spiritual support $[1,2]$. Given the lack of curative treatment and the limited life expectancy, the overriding aim with MPM is to maintain quality of life and allow patients to live a meaningful and dignified life [1]. A multicentre randomised controlled trial is currently underway evaluating whether early specialist palliative care involvement improves patient-reported quality of life in MPM [136].

\section{Future therapies}

Numerous novel agents have been investigated in MPM. Amongst those that have demonstrated efficacy are targeted therapies to epidermal growth factor receptor antagonists and platelet-derived growth factor receptor inhibitors. However, more accurate tumour profiling and identification of biomarkers are needed in order to identify the patients most likely to respond [137-140].

Immunotherapy has shown promise in MPM. Checkpoint inhibitors such as tremelimumab and pembrolizumab have shown impressive disease control rates and prolonged disease stability when used as first-, second- or third-line treatment [141-145]. The combination of chemotherapy with immunotherapy, or multiple immunotherapy agents, appears synergistic in other tumours and warrants further exploration in MPM [146-148]. Numerous trials are currently underway exploring alternate immunotherapy agents and combinations (www.clinicaltrials.gov).

Mesothelin-targeted treatments are another area of interest in MPM. Agents that have undergone early phase clinical trials include mesothelin-specific monoclonal antibodies (e.g. amatuximab), anti-mesothelin immunotoxins (e.g. SS1P), mesothelin tumour vaccine (CRS-207) and chimeric antigen receptor T-cells targeted to mesothelin [149-153]. Phase II and III trials are underway.

FIGURE 4 Talc poudrage seen at thoracoscopy. A: parietal pleura with ribs visible beneath and a fine layer of talc covering most of its surface. B: malignant-looking nodule on the parietal pleura. C: collapsed lung with talc covering its surface. D: talc collecting in the para-spinal gutter.

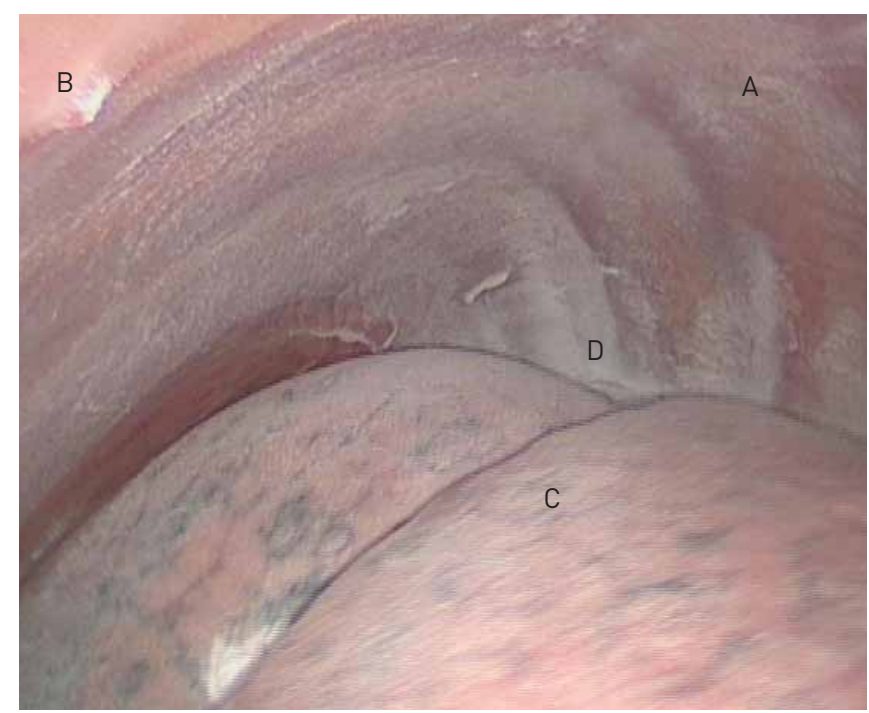


Finally intra-pleural gene therapy using an adenovirus vector has been shown to be safe and feasible in MPM, with promising median survival in a pilot study of 40 patients [154]. A multicentre randomised trial is planned.

Overall, the future of MPM looks likely to contain many more therapeutic options than are currently available. Personalised treatment based on individual patient characteristics and tumour genetics is distinctly possible. Combination therapy is likely to generate a significant breakthrough in the next few years.

\section{Conclusion}

MPM is a complex disease that causes significant morbidity and mortality. Diagnostic difficulties complicate matters, although there is potential for developments in the field of imaging and biomarkers in the next few years. Treatment options remain limited, but the recent trial supporting the use of the targeted therapy bevacizumab has given hope that this may be changing. Many new treatments are under investigation and it is likely that the future of MPM will involve highly individual, personalised treatment.

\section{References}

1 British Thoracic Society Standards of Care Committee. BTS statement on malignant mesothelioma in the UK, 2007. Thorax 2007; 62: Suppl 2, ii1-ii19.

2 Scherpereel A, Astoul P, Baas P, et al. Guidelines of the European Respiratory Society and the European Society of Thoracic Surgeons for the management of malignant pleural mesothelioma. Eur Respir J 2010; 35: 479-495.

3 Yates D, Corrin B, Stidolph P, et al. Malignant mesothelioma in south east England: clinicopathological experience of 272 cases. Thorax 1997; 52: 507-512.

4 Howel D, Arblaster L, Swinburne L, et al. Routes of asbestos exposure and the development of mesothelioma in an English region. Occup Environ Med 1997; 54: 403-409.

Sekido Y. Molecular pathogenesis of malignant mesothelioma. Carcinogenesis 2013; 34: 1413-1419.

Park EK, Takahashi K, Hoshuyama T, et al. Global magnitude of reported and unreported mesothelioma. Environ Health Perspect 2011; 119: 514.

7 Beckett P, Edwards J, Fennell D, et al. Demographics, management and survival of patients with malignant pleural mesothelioma in the National Lung Cancer Audit in England and Wales. Lung Cancer 2015; 88: 344-348. Carbone M, Emri S, Dogan AU, et al. A mesothelioma epidemic in Cappadocia: scientific developments and unexpected social outcomes. Nat Rev Cancer 2007; 7: 147-154.

9 van Kaick G, Dalheimer A, Hornik S, et al. The German thorotrast study: recent results and assessment of risks. Radiat Res 1999; 152: Suppl 6, S64-S71.

10 López-Ríos F, Illei PB, Rusch V, et al. Evidence against a role for SV40 infection in human mesotheliomas and high risk of false-positive PCR results owing to presence of SV40 sequences in common laboratory plasmids. Lancet 364: 1157-1166.

11 Carbone M, Pass HI, Rizzo P, et al. Simian virus 40-like DNA sequences in human pleural mesothelioma. Oncogene 1994; 9: 1781-1790.

12 Cicala C, Pompetti F, Carbone M. SV40 induces mesotheliomas in hamsters. Am J Pathol 1993; 142: 1524-1533.

13 Robinson BW, Lake RA. Advances in malignant mesothelioma. N Engl J Med 2005; 353: 1591-1603.

14 Illei PB, Rusch VW, Zakowski MF, et al. Homozygous deletion of CDKN2A and codeletion of the methylthioadenosine phosphorylase gene in the majority of pleural mesotheliomas. Clin Cancer Res 2003; 9: 2108-2113.

15 Guo G, Chmielecki J, Goparaju C, et al. Whole-exome sequencing reveals frequent genetic alterations in BAP1, NF2, CDKN2A, and CUL1 in malignant pleural mesothelioma. Cancer Res 2015; 75: 264-269.

16 Torti $\mathrm{D}$, Trusolino L. Oncogene addiction as a foundational rationale for targeted anti-cancer therapy: promises and perils. EMBO Mol Med 2011; 3: 623-636.

17 Arber A, Spencer L. 'It's all bad news': the first 3 months following a diagnosis of malignant pleural mesothelioma. Psychooncology 2013; 22: 1528-1533.

18 Clayson H, Seymour J, Noble B. Mesothelioma from the patient's perspective. Hematol Oncol Clin North Am 2005; 19: 1175-1190.

19 Lee S, O'Connor M, Chapman Y, et al. A very public death: dying of mesothelioma and asbestos-related lung cancer (M/ARLC) in the Latrobe Valley, Victoria, Australia. Rural Remote Health 2009; 9: 1183.

20 Chapman E, Hughes D, Landy A, et al. Challenging the representations of cancer pain: experiences of a multidisciplinary pain management group in a palliative care unit. Palliat Support Care 2005; 3: 43-49.

21 Lebovits AH, Chahinian AP, Holland JC. Exposure to asbestos: psychological responses of mesothelioma patients. Am J Ind Med 1983; 4: 459-466.

22 Clayson H. Suffering in mesothelioma: concepts and contexts. Prog Palliat Care 2003; 11: 251-255.

23 Hawley R, Monk A, Wiltshire J. The mesothelioma journey: developing strategies to meet the needs of people with mesothelioma, their family carers and health professionals involved in their care. Nursing Research Centre for Adaptation in Health and Illness, Sydney, 2004.

24 Hughes N, Arber A. The lived experience of patients with pleural mesothelioma. Int J Palliat Nurs 2008; 14; $66-71$.

25 Rudd RM. Malignant mesothelioma. Br Med Bull 2010; 93: 105-123.

26 Nowak AK, Stockler MR, Byrne MJ. Assessing quality of life during chemotherapy for pleural mesothelioma: feasibility, validity, and results of using the European Organization for Research and Treatment of Cancer Core Quality of Life Questionnaire and Lung Cancer Module. J Clin Oncol 2004; 22: 3172-3180. van Zandwijk N, Clarke C, Henderson D, et al. Guidelines for the diagnosis and treatment of malignant pleural mesothelioma. J Thorac Dis 2013; 5: E254-E307.

28 Muers MF, Stephens RJ, Fisher P, et al. Active symptom control with or without chemotherapy in the treatment of patients with malignant pleural mesothelioma (MS01): a multicentre randomised trial. Lancet 2008; 371: 1685-1694. 
O'Brien ME, Watkins D, Ryan C, et al. A randomised trial in malignant mesothelioma (M) of early (E) versus delayed (D) chemotherapy in symptomatically stable patients: the MED trial. Ann Oncol 2006; 17: 270-275.

30 Roberts ME, Neville E, Berrisford RG, et al. Management of a malignant pleural effusion: British Thoracic Society pleural disease guideline 2010. Thorax 2010; 65: Suppl 2, ii32-ii40.

31 Clayson H. The experience of mesothelioma in Northern England. PhD thesis. University of Sheffield, Sheffield, UK. 2007.

32 Hillerdal G. Malignant mesothelioma 1982: review of 4710 published cases. Br J Dis Chest 1983; 77: $321-343$.

33 Inui A. Cancer anorexia-cachexia syndrome: current issues in research and management. CA Cancer J Clin 2002; 52: 72-91.

34 Herndon JE, Green MR, Chahinian AP, et al. Factors predictive of survival among 337 patients with mesothelioma treated between 1984 and 1994 by the Cancer and Leukemia Group B. Chest 1998; 113: 723-731.

35 Renshaw AA, Dean BR, Cibas ES, et al. The role of cytologic evaluation of pleural fluid in the diagnosis of malignant mesothelioma. Chest 1997; 111: 106-109.

36 Lin K, Croswell JM, Koenig H, et al. Prostate-specific antigen-based screening for prostate cancer: an evidence update for the US Preventive Services Task Force. Agency for Research Health and Quality, Rockville, MD, 2011.

37 Early Breast Cancer Trialists Collaborative Group, Davies C, Godwin J, et al. Relevance of breast cancer hormone receptors and other factors to the efficacy of adjuvant tamoxifen: patient-level meta-analysis of randomised trials. Lancet 2011; 378: 771-784.

38 Hooper C, Lee YC, Maskell N. Investigation of a unilateral pleural effusion in adults: British Thoracic Society Pleural Disease Guideline 2010. Thorax 2010; 65: Suppl 2, ii4-i17.

39 Bibby AC, Maskell NA. Pleural biopsies in undiagnosed pleural effusions; Abrams vs image-guided vs thoracoscopic biopsies. Curr Opin Pulm Med 2016; 22: 392-398.

40 Heelan R, Rusch V, Begg C, et al. Staging of malignant pleural mesothelioma: comparison of CT and MR imaging. AJR Am J Roentgenol 1999; 172: 1039-1047.

41 Rusch VW. A proposed new international TNM staging system for malignant pleural mesothelioma. Chest 1995; 108: $1122-1128$.

42 Salonen O, Kivisaari L, Standertskjöld-Nordenstam C-G, et al. Computed tomography of pleural lesions with special reference to the mediastinal pleura. Acta Radiologica Diagnosis (Sweden) 1986; 27: 527-531.

43 Havelock T, Teoh R, Laws D, et al. Pleural procedures and thoracic ultrasound: British Thoracic Society pleural disease guideline 2010. Thorax 2010; 65: Suppl 2, i61-i76.

44 Qureshi NR, Rahman NM, Gleeson FV. Thoracic ultrasound in the diagnosis of malignant pleural effusion. Thorax 2009; 64: 139-143.

45 Hierholzer J, Luo L, Bittner RC, et al. MRI and CT in the differential diagnosis of pleural disease. Chest J 2000; 118: 604-609.

46 Rahman NM, Pepperell J, Rehal S, et al. Effect of opioids vs NSAIDs and larger $v s$ smaller chest tube size on pain control and pleurodesis efficacy among patients with malignant pleural effusion: the TIME1 randomized clinical trial. JAMA 2015; 314: 2641-2653.

47 Metintas M, Ucgun I, Elbek O, et al. Computed tomography features in malignant pleural mesothelioma and other commonly seen pleural diseases. Eur J Radiol 2002; 41: 1-9.

48 Seely JM, Nguyen ET, Churg AM, et al. Malignant pleural mesothelioma: computed tomography and correlation with histology. Eur J Radiol 2009; 70: 485-491.

49 Şenyiğit A, Bayram H, Babayiğit C, et al. Malignant pleural mesothelioma caused by environmental exposure to asbestos in the Southeast of Turkey: CT findings in 117 patients. Respiration 2000; 67: 615-622.

50 Rusch VW, Giroux D, Kennedy C, et al. Initial analysis of the international association for the study of lung cancer mesothelioma database. J Thorac Oncol 2012; 7: 1631-1639.

51 Benard F, Sterman D, Smith RJ, et al. Metabolic imaging of malignant pleural mesothelioma with fluorodeoxyglucose positron emission tomography. Chest J 1998; 114: 713-722.

52 Yildirim H, Metintas M, Entok E, et al. Clinical value of fluorodeoxyglucose-positron emission tomography/ computed tomography in differentiation of malignant mesothelioma from asbestos-related benign pleural disease: an observational pilot study. J Thorac Oncol 2009; 4: 1480-1484.

53 Treglia G, Sadeghi R, Annunziata S, et al. Diagnostic accuracy of 18F-FDG-PET and PET/CT in the differential diagnosis between malignant and benign pleural lesions: a systematic review and meta-analysis. Acad Radiol 2014; 21: 11-20.

54 Porcel JM, Hernández P, Martínez-Alonso M, et al. Accuracy of fluorodeoxyglucose-PET imaging for differentiating benign from malignant pleural effusions: a meta-analysis. Chest 2015; 147: 502-512.

55 Plathow C, Staab A, Schmaehl A, et al. Computed tomography, positron emission tomography, positron emission tomography/computed tomography, and magnetic resonance imaging for staging of limited pleural mesothelioma: initial results. Invest Radiol 2008; 43: 737-744.

56 Flores RM, Akhurst T, Gonen M, et al. Positron emission tomography defines metastatic disease but not locoregional disease in patients with malignant pleural mesothelioma. J Thorac Cardiovasc Surg 2003; 126 : 11-15.

57 Stewart D, Waller D, Edwards J, et al. Is there a role for pre-operative contrast-enhanced magnetic resonance imaging for radical surgery in malignant pleural mesothelioma? Eur J CardioThorac Surg 2003; 24: 1019-1024.

58 Coolen J, De Keyzer F, Nafteux P, et al. Malignant pleural disease: diagnosis by using diffusion-weighted and dynamic contrast-enhanced MR imaging - initial experience. Radiology 2012; 263: 884-892.

59 Coolen J, De Keyzer F, Nafteux P, et al. Malignant pleural mesothelioma: visual assessment by using pleural pointillism at diffusion-weighted MR imaging. Radiology 2014; 274: 576-584.

60 Chang K, Pai LH, Batra JK, et al. Characterization of the antigen (CAK1) recognized by monoclonal antibody K1 present on ovarian cancers and normal mesothelium. Cancer Res 1992; 52: 181-186.

61 Chang K, Pai L, Pass H, et al. Monoclonal antibody K1 reacts with epithelial mesothelioma but not with lung adenocarcinoma. Lung Cancer 1993; 8: 336.

62 Creaney J, Yeoman D, Demelker Y, et al. Comparison of osteopontin, megakaryocyte potentiating factor, and mesothelin proteins as markers in the serum of patients with malignant mesothelioma. J Thorac Oncol 2008; 3: 851-857.

63 Creaney J, Robinson BW. Detection of malignant mesothelioma in asbestos-exposed individuals: the potential role of soluble mesothelin-related protein. Hematol Oncol Clin North Am 19: 1025-1040. 
Hollevoet K, Reitsma JB, Creaney J, et al. Serum mesothelin for diagnosing malignant pleural mesothelioma: an individual patient data meta-analysis. J Clin Oncol 2012; 30: 1541-1549.

Cui A, Jin X-G, Zhai K, et al. Diagnostic values of soluble mesothelin-related peptides for malignant pleural mesothelioma: updated meta-analysis. BMJ Open 2014; 4: e004145.

Creaney J, Dick IM, Meniawy TM, et al. Comparison of fibulin-3 and mesothelin as markers in malignant mesothelioma. Thorax 2014; 69: 895-902.

Pass HI, Levin SM, Harbut MR, et al. Fibulin-3 as a blood and effusion biomarker for pleural mesothelioma. N Engl J Med 2012; 367: 1417-1427.

Hollevoet K, Nackaerts K, Thimpont J, et al. Diagnostic performance of soluble mesothelin and megakaryocyte potentiating factor in mesothelioma. Am J Respir Crit Care Med 2010; 181: 620-625.

Ostroff RM, Mehan MR, Stewart A, et al. Early detection of malignant pleural mesothelioma in asbestos-exposed individuals with a noninvasive proteomics-based surveillance tool. PLoS One 2012; 7: e46091.

Department of Health. Mesothelioma Service Framework. Dept of Health Lung Cancer and Mesothelioma Advisory Group, London, 2007.

Bibby AC, Williams K, Smith S, et al. What is the role of a specialist regional mesothelioma multidisciplinary team meeting? A service evaluation of one tertiary referral centre in the UK. BMJ Open 2016; 6: e012092.

Bibby AC, Gibbs L, Braybrooke JP. Medical and oncological management of malignant mesothelioma. $\mathrm{Br} J \mathrm{Hosp}$ Med (Lond) 2015; 76: 384-389.

Fennell DA, Gaudino G, O'Byrne KJ, et al. Advances in the systemic therapy of malignant pleural mesothelioma. Nat Clin Pract Oncol 2008; 5: 136-147.

Vogelzang NJ, Rusthoven JJ, Symanowski J, et al. Phase III study of pemetrexed in combination with cisplatin versus cisplatin alone in patients with malignant pleural mesothelioma. J Clin Oncol 2003; 21: 2636-2644.

van Meerbeeck JP, Gaafar R, Manegold C, et al. Randomized phase III study of cisplatin with or without raltitrexed in patients with malignant pleural mesothelioma: an intergroup study of the European Organisation for Research and Treatment of Cancer Lung Cancer Group and the National Cancer Institute of Canada. J Clin Oncol 2005; 23: 6881-6889.

Berghmans T, Paesmans M, Lalami Y, et al. Activity of chemotherapy and immunotherapy on malignant mesothelioma: a systematic review of the literature with meta-analysis. Lung Cancer 2002; 38: 111-121.

Ceresoli GL, Zucali PA, Favaretto AG, et al. Phase II study of pemetrexed plus carboplatin in malignant pleural mesothelioma. J Clin Oncol 2006; 24: 1443-1448.

Ceresoli GL, Castagneto B, Zucali PA, et al. Pemetrexed plus carboplatin in elderly patients with malignant pleural mesothelioma: combined analysis of two phase II trials. Br J Cancer 2008; 99: 51-56.

Castagneto B, Botta M, Aitini E, et al. Phase II study of pemetrexed in combination with carboplatin in patients with malignant pleural mesothelioma (MPM). Ann Oncol 2008; 19: 370-373.

Santoro A, O'Brien ME, Stahel RA, et al. Pemetrexed plus cisplatin or pemetrexed plus carboplatin for chemonaive patients with malignant pleural mesothelioma: results of the International Expanded Access Program. J Thorac Oncol 2008; 3: 756-763.

Socinski MA, Schell MJ, Peterman A, et al. Phase III trial comparing a defined duration of therapy versus continuous therapy followed by second-line therapy in advanced-stage IIIb/IV non-small-cell lung cancer. J Clin Oncol 2002; 20: 1335-1343.

van den Bogaert DP, Pouw EM, van Wijhe G, et al. Pemetrexed maintenance therapy in patients with malignant pleural mesothelioma. J Thorac Oncol 2006; 1: 25-30.

Stebbing J, Powles T, McPherson K, et al. The efficacy and safety of weekly vinorelbine in relapsed malignant pleural mesothelioma. Lung Canc 2009; 63: 94-97.

Nowak A, Byrne M, Williamson R, et al. A multicentre phase II study of cisplatin and gemcitabine for malignant mesothelioma. Br J Cancer 2002; 87: 491-496.

Castagneto B, Zai S, Dongiovanni D, et al. Cisplatin and gemcitabine in malignant pleural mesothelioma: a phase II study. Am J Clin Oncol 2005; 28: 223-226.

Jassem J, Ramlau R, Santoro A, et al. Phase III trial of pemetrexed plus best supportive care compared with best supportive care in previously treated patients with advanced malignant pleural mesothelioma. J Clin Oncol 2008; 26: $1698-1704$.

Ceresoli GL, Zucali PA, De Vincenzo F, et al. Retreatment with pemetrexed-based chemotherapy in patients with malignant pleural mesothelioma. Lung Cancer 2011; 72: 73-77.

Ohta Y, Shridhar V, Bright RK, et al. VEGF and VEGF type C play an important role in angiogenesis and lymphangiogenesis in human malignant mesothelioma tumours. Br J Cancer 1999; 81: 54-61.

Zalcman G, Mazieres J, Margery J, et al. Bevacizumab for newly diagnosed pleural mesothelioma in the Mesothelioma Avastin Cisplatin Pemetrexed Study (MAPS): a randomised, controlled, open-label, phase 3 trial. Lancet 2016; 387: 1405-1414.

Zauderer MG. A new standard for malignant pleural mesothelioma. Lancet 2016; 387: 1352-1354.

Rimner A, Zauderer MG, Gomez DR, et al. Phase II study of Hemithoracic Intensity-Modulated Pleural Radiation Therapy (IMPRINT) as part of lung-sparing multimodality therapy in patients with malignant pleural mesothelioma. J Clin Oncol 2016; 34: 2761-2768.

MacLeod N, Chalmers A, O’Rourke N, et al. Is radiotherapy useful for treating pain in mesothelioma? A phase II trial. J Thorac Oncol 2015; 10: 944-950.

Boutin C, Rey F, Viallat JR. Prevention of malignant seeding after invasive diagnostic procedures in patients with pleural mesothelioma. A randomized trial of local radiotherapy. Chest 1995; 108: 754-758.

Bydder S, Phillips M, Joseph DJ, et al. A randomised trial of single-dose radiotherapy to prevent procedure tract metastasis by malignant mesothelioma. Br J Cancer 2004; 91: 9-10.

O'Rourke N, Garcia JC, Paul J, et al. A randomised controlled trial of intervention site radiotherapy in malignant pleural mesothelioma. Radiother Oncol 2007; 84: 18-22.

Treasure T, Sedrakyan A. Pleural mesothelioma: little evidence, still time to do trials. Lancet 364: 1183-1185. Clive AO, Taylor H, Dobson L, et al. Prophylactic radiotherapy for the prevention of procedure-tract metastases after surgical and large-bore pleural procedures in malignant pleural mesothelioma (SMART): a multicentre, open-label, phase 3, randomised controlled trial. Lancet Oncol 2016; 17: 1094-1104. 

mesothelioma of the pleura. Experience with 29 patients. Thorax 1976; 31: 15-24.

Sugarbaker DJ, Garcia JP, Richards WG, et al. Extrapleural pneumonectomy in the multimodality therapy of malignant pleural mesothelioma. Results in 120 consecutive patients. Ann Surg 1996; 224: 288-294.

100 Sugarbaker DJ, Jaklitsch MT, Bueno R, et al. Prevention, early detection, and management of complications after 328 consecutive extrapleural pneumonectomies. J Thorac Cardiovasc Surg 2004; 128: 138-146.

101 Opitz I, Kestenholz P, Lardinois D, et al. Incidence and management of complications after neoadjuvant chemotherapy followed by extrapleural pneumonectomy for malignant pleural mesothelioma. Eur J Cardiothorac Surg 2006; 29: 579-584.

102 Maziak DE, Gagliardi A, Haynes AE, et al. Surgical management of malignant pleural mesothelioma: a systematic review and evidence summary. Lung Cancer 2005; 48: 157-169.

103 Treasure T, Lang-Lazdunski L, Waller D, et al. Extra-pleural pneumonectomy versus no extra-pleural pneumonectomy for patients with malignant pleural mesothelioma: clinical outcomes of the Mesothelioma and Radical Surgery (MARS) randomised feasibility study. Lancet Oncol 2011; 12: 763-772.

104 Flores RM. Pleurectomy decortication for mesothelioma: the procedure of choice when possible. $J$ Thorac Cardiovasc Surg 2016; 151: 310-312.

105 Batirel HF, Metintas M, Caglar HB, et al. Adoption of pleurectomy and decortication for malignant mesothelioma leads to similar survival as extrapleural pneumonectomy. J Thorac Cardiovasc Surg 2016; 151: 478-484.

106 Flores RM. The mesothelioma surgery shift. J Thorac Cardiovasc Surg 2016; 151: 485-486.

107 Flores RM, Pass HI, Seshan VE, et al. Extrapleural pneumonectomy versus pleurectomy/decortication in the surgical management of malignant pleural mesothelioma: results in 663 patients. J Thorac Cardiovasc Surg 2008; 135: 620-626.

108 Cao C, Tian D, Park J, et al. A systematic review and meta-analysis of surgical treatments for malignant pleural mesothelioma. Lung Cancer 2014; 83: 240-245.

109 Lang-Lazdunski L, Bille A, Lal R, et al. Pleurectomy/decortication is superior to extrapleural pneumonectomy in the multimodality management of patients with malignant pleural mesothelioma. J Thorac Oncol 2012; 7: $737-743$.

110 Rusch V, Saltz L, Venkatraman E, et al. A phase II trial of pleurectomy/decortication followed by intrapleural and systemic chemotherapy for malignant pleural mesothelioma. J Clin Oncol 1994; 12: 1156-1163.

111 Pass HI, Temeck BK, Kranda K, et al. Phase III randomized trial of surgery with or without intraoperative photodynamic therapy and postoperative immunochemotherapy for malignant pleural mesothelioma. Ann Surg Oncol 1997; 4: 628-633.

112 Richards WG, Zellos L, Bueno R, et al. Phase I to II study of pleurectomy/decortication and intraoperative intracavitary hyperthermic cisplatin lavage for mesothelioma. J Clin Oncol 2006; 24: 1561-1567.

113 Rusch VW, Rosenzweig K, Venkatraman E, et al. A phase II trial of surgical resection and adjuvant highdose hemithoracic radiation for malignant pleural mesothelioma. J Thorac Cardiovasc Surg 2001; 122: 788-795.

114 Lim E. MARS 2: A Feasibility Study Comparing (Extended) Pleurectomy Decortication Versus no Pleurectomy Decortication in Patients With Malignant Pleural Mesothelioma (MARS2). NCT02040272. https://clinicaltrials. gov/ct2/show/NCT02040272 Date last updated: April 12 2016. Date last accessed: October 282016.

115 Nakas A, Martin Ucar AE, Edwards JG, et al. The role of video assisted thoracoscopic pleurectomy/decortication in the therapeutic management of malignant pleural mesothelioma. Eur J CardioThorac Surg 2008; 33: 83-88.

116 Halstead JC, Lim E, Venkateswaran RM, et al. Improved survival with VATS pleurectomy-decortication in advanced malignant mesothelioma. Eur J Surg Oncol 2005; 31: 314-320.

117 Rintoul RC, Ritchie AJ, Edwards JG, et al. Efficacy and cost of video-assisted thoracoscopic partial pleurectomy versus talc pleurodesis in patients with malignant pleural mesothelioma (MesoVATS): an open-label, randomised, controlled trial. Lancet 384: 1118-1127.

118 Krug LM, Pass HI, Rusch VW, et al. Multicenter phase II trial of neoadjuvant pemetrexed plus cisplatin followed by extrapleural pneumonectomy and radiation for malignant pleural mesothelioma. J Clin Oncol 2009; 27: 3007-3013.

119 Van Schil PE, Baas P, Gaafar R, et al. Trimodality therapy for malignant pleural mesothelioma: results from an EORTC phase II multicentre trial. Eur Respir J 2010; 36: 1362-1369.

120 Cao C, Tian D, Manganas C, et al. Systematic review of trimodality therapy for patients with malignant pleural mesothelioma. Ann Cardiothorac Surg 2012; 1: 428-437.

121 Stahel RA, Riesterer O, Xyrafas A, et al. Neoadjuvant chemotherapy and extrapleural pneumonectomy of malignant pleural mesothelioma with or without hemithoracic radiotherapy (SAKK 17/04): a randomised, international, multicentre phase 2 trial. Lancet Oncol 16: 1651-1658.

122 Cho BC, Feld R, Leighl N, et al. A feasibility study evaluating surgery for mesothelioma after radiation therapy: the "SMART" approach for resectable malignant pleural mesothelioma. J Thorac Oncol 2014; 9: $397-402$.

123 de Perrot M, Feld R, Leighl NB, et al. Accelerated hemithoracic radiation followed by extrapleural pneumonectomy for malignant pleural mesothelioma. J Thorac Cardiovasc Surg 2016; 151: 468-475.

124 Davies HE, Mishra EK, Kahan BC, et al. Effect of an indwelling pleural catheter vs chest tube and talc pleurodesis for relieving dyspnea in patients with malignant pleural effusion: the TIME2 randomized controlled trial. JAMA 2012; 307: 2383-2389.

125 Walker-Renard PB, Vaughan LM, Sahn SA. Chemical pleurodesis for malignant pleural effusions. Ann Intern Med 1994; 120: 56-64.

126 Ong KC, Indumathi V, Raghuram J, et al. A comparative study of pleurodesis using talc slurry and bleomycin in the management of malignant pleural effusions. Respirology 2000; 5: 99-103.

127 Fuller DK. Bleomycin versus doxycycline: a patient-oriented approach to pleurodesis. Ann Pharmacother 1993; 27: 794.

128 Keeratichananont W, Limthon T, Keeratichananont S. Efficacy and safety profile of autologous blood versus tetracycline pleurodesis for malignant pleural effusion. Therap Adv Respir Dis 2015; 9: 42-48.

129 Clive $\mathrm{AO}$, Jones $\mathrm{HE}$, Bhatnagar $\mathrm{R}$, et al. Interventions for the management of malignant pleural effusions: a network meta-analysis. Cochrane Database Syst Rev 2016; 71: 964-966. 
Antony V, Loddenkemper R, Astoul P, et al. Management of malignant pleural effusions. Eur Respir J 2001; 18: 402-419.

Kennedy L, Rusch VW, Strange C, et al. Pleurodesis using talc slurry. Chest 1994; 106: 342-346.

Manes N, Rodriguez-Panadero F, Bravo JL, et al. Talc pleurodesis. Prospective and randomized study. Clinical follow-up. Chest 2000; 118: 131S-131S.

Dresler C, Olak J, Herndon JII, et al. Phase III intergroup study of talc poudrage vs talc slurry sclerosis for malignant pleural effusion. Chest 2005; 127: 909-915.

Clive A, Jones H, Bhatnagar R, et al. S19 interventions for the management of malignant pleural effusions. Thorax 2015; 70: Suppl 3, A15.

Maskell NA. Treatment options for malignant pleural effusions: patient preference does matter. JAMA 2012; 307: $2432-2433$.

Gunatilake S, Brims FJ, Fogg C, et al. A multicentre non-blinded randomised controlled trial to assess the impact of regular early specialist symptom control treatment on quality of life in malignant mesothelioma (RESPECT-MESO): study protocol for a randomised controlled trial. Trials 2014; 15: 367.

Garland LL, Rankin C, Gandara DR, et al. Phase II study of erlotinib in patients with malignant pleural mesothelioma: a Southwest Oncology Group Study. J Clin Oncol 2007; 25: 2406-2413.

Govindan R, Kratzke RA, Herndon JE, et al. Gefitinib in patients with malignant mesothelioma: a phase II study by the Cancer and Leukemia Group B. Clin Cancer Res 2005; 11: 2300-2304.

Mathy A, Baas P, Dalesio O, et al. Limited efficacy of imatinib mesylate in malignant mesothelioma: a phase II trial. Lung Cancer 2005; 50: 83-86.

Nowak AK, Millward MJ, Creaney J, et al. A phase II study of intermittent sunitinib malate as second-line therapy in progressive malignant pleural mesothelioma. J Thorac Oncol 2012; 7: 1449-1456.

Calabro L, Morra A, Fonsatti E, et al. Tremelimumab for patients with chemotherapy-resistant advanced malignant mesothelioma: an open-label, single-arm, phase 2 trial. Lancet Oncol 2013; 14: 1104-1111.

Calabrò L, Morra A, Fonsatti E, et al. Efficacy and safety of an intensified schedule of tremelimumab for chemotherapy-resistant malignant mesothelioma: an open-label, single-arm, phase 2 study. Lancet Respir Med 2015; 3: 301-309.

3 Alley EW, Molife LR, Santoro A, et al. Clinical safety and efficacy of pembrolizumab (MK-3475) in patients with malignant pleural mesothelioma: preliminary results from KEYNOTE-028. Cancer Res 2015; 75: Suppl. 15, CT103.

4 Kindler HL, Karrison T, Khattri A, et al. Phase II Study of the Anti-PD-1 Antibody Pembrolizumab in Patients with Malignant Mesothelioma. J Thorac Oncol 2015; 10: S630.

Cornelissen R, Scherpereel A, Pietro AD, et al. Randomised, double-blind, placebo-controlled study of tremelimumab for second- and third-line treatment of unresectable pleural or peritoneal mesothelioma. J Clin Oncol 2014; 32: TPS7609.

Emens LA, Middleton G. The Interplay of immunotherapy and chemotherapy: harnessing potential synergies. Cancer Immunol Res 2015; 3: 436-443.

Calabrò L, Morra A, Fonsatti E, et al. 16TiPA phase II study combining tremelimumab and durvalumab (MEDI4736) immunomodulating antibodies in mesothelioma patients: the NIBIT-MESO-1 study. Ann Oncol 2015; 26: Suppl 8, viii6-vviii.

Larkin J, Chiarion-Sileni V, Gonzalez R, et al. Combined nivolumab and ipilimumab or monotherapy in untreated melanoma. N Engl J Med 2015; 373: 23-34.

Hassan R, Schweizer C, Lu KF, et al. Inhibition of mesothelin-CA-125 interaction in patients with mesothelioma by the anti-mesothelin monoclonal antibody MORAb-009: Implications for cancer therapy. Lung Cancer 2010; 68: 455-459.

0 Hassan R, Kindler HL, Jahan T, et al. Phase II clinical trial of amatuximab, a chimeric antimesothelin antibody with pemetrexed and cisplatin in advanced unresectable pleural mesothelioma. Clin Cancer Res 2014; 20: 5927-5936.

51 Hassan R, Sharon E, Thomas A, et al. Phase 1 study of the antimesothelin immunotoxin SS1P in combination with pemetrexed and cisplatin for front-line therapy of pleural mesothelioma and correlation of tumor response with serum mesothelin, megakaryocyte potentiating factor, and cancer antigen 125. Cancer 2014; 120: 3311-3319.

52 Hassan R, Antonia SJ, Alley EW, et al., editors. Mesothelin-targeted immunotherapy CRS-207 in combination with standard of care chemotherapy as treatment for malignant pleural mesothelioma (MPM). J Clin Oncol 2015; 33: 7565.

53 Beatty GL, Haas AR, Maus MV, et al. Mesothelin-specific chimeric antigen receptor MRNA-engineered T cells induce antitumor activity in solid malignancies. Cancer Immunol Res 2014; 2: 112-120.

Sterman DH, Alley E, Stevenson JP, et al. Pilot and feasibility trial of immuno-gene therapy of malignant mesothelioma using intrapleural dlivery of adenovirus-interferon- $\alpha$ combined with chemotherapy. Clin Cancer Res 2016; 22: 3791-3800. 